\title{
Identifying and managing functional cardiac symptoms
}

\author{
Authors: Jonathan Rogers, ${ }^{A}$ George Collins, ${ }^{B}$ Mujtaba Husain ${ }^{C}$ and Mary Docherty ${ }^{C}$
}

\begin{abstract}
Recurring chest pain and other cardiac symptoms that cannot be adequately explained by organic pathology are common and can be associated with substantial disability, distress and high healthcare costs. Common mental disorders such as depression and anxiety frequently co-occur with these symptoms and, in some cases, account for their presentation, although they are not universally present. Due to the frequency of functional cardiac presentations and risks of iatrogenic harm, physicians should be familiar with strategies to identify, assess and communicate with patients about these symptoms. A systematic and multidisciplinary approach to diagnosis and management is often needed. Health beliefs, concerns and any associated behaviours should be elicited and addressed throughout. Psychiatric comorbidities should be concurrently identified and treated. For those with persistent symptoms, psychosocial outcomes can be poor, highlighting the need for further research and investment in diagnostic and therapeutic approaches and multidisciplinary service models.
\end{abstract}

KEYWORDS: cardiac, functional symptoms, psychosomatics

DOI: $10.7861 /$ clinmed.2020-0934

\section{Introduction}

Experiencing a symptom suggestive of heart disease or being investigated for or diagnosed with any type of cardiac problem is frightening. While this may seem an obvious statement, it is a fact sometimes forgotten in clinical practice. Nearly a century ago, Auerback citing Conor noted 'The psychic reaction to doubt concerning the integrity of the heart ... seems to be much more violent and profound than is the case with any of the other internal organs." The uniquely emotive nature of cardiac symptoms may be one of several factors contributing to both the suspected high rates of cardiac symptoms in somatoform

Authors: ${ }^{A}$ Wellcome Trust clinical training fellow, University College London, London, UK and specialty registrar in general adult and old age psychiatry, South London and Maudsley NHS Foundation Trust, London, UK; ${ }^{B}$ Wellcome Trust clinical training fellow, University College London, London, UK and specialty registrar in cardiology, Barts Health NHS Trust, London, UK; ' ${ }^{\text {Consultant in }}$ liaison psychiatry, South London and Maudsley NHS Foundation Trust, London, UK disorders and high levels of psychiatric comorbidity (such as depression and anxiety) associated with cardiac symptoms of either an organic or non-organic origin. ${ }^{2,3}$

Diagnosis and management of functional cardiac symptoms is challenging. It requires delineation between multiple potential physical conditions (including cardiac, gastrointestinal, musculoskeletal, respiratory, neurological, vascular and haematological disorders), somatic symptoms of a psychiatric disorder (such as anxiety, depression, panic attack or posttraumatic stress disorder) or a combination of these issues. Awareness of, sensitivity to and curiosity about beliefs and health attributions that patients hold regarding the meaning of their symptoms is the first principle of assessment and management. These should be directly elicited and addressed throughout investigation, diagnosis and treatment. The language, clinical approach and information given in consultations may have an impact on both patient experience and illness course, including persistence of symptoms and use of healthcare services. ${ }^{1,4-8}$ It is critically important that clinicians recognise and acknowledge the reality and impact of these symptoms on patients. ${ }^{9}$

\section{Clinical presentation and classification}

Common symptoms include non-cardiac chest pain (NCCP), palpitations, breathlessness and syncope. There is substantial variation in presentation and severity. ${ }^{10}$ Some patients present with a single symptom (such as NCCP) while others present with multiple symptoms (such as fatigue, chest pain, shortness of breath and palpitations). Severity ranges from minor distress or concern with resolution of symptoms to persistent symptoms, severe distress, associated disability and extremely high healthcare use. ${ }^{11-14}$

There is ongoing debate over how best to classify these presentations and the terminology used to describe them. ${ }^{15-18}$ Approaches have included description of syndromes involving one symptom (eg NCCP), several symptoms ('bodily distress syndrome') compatible with the cardiopulmonary system and symptoms involving multiple body systems. ${ }^{19,20}$ Classification systems based on prognostic factors (eg self-limiting versus recurrent and persistent symptoms) have been suggested to have practical benefits. ${ }^{10}$

NCCP (also known as syndrome $X$ and non-specific chest pain) is defined as angina-like chest pain without evidence of epicardial coronary artery disease. ${ }^{21-23}$ The finding that $82 \%$ of patients with NCCP who had had gastrointestinal causes excluded as a cause for the pain also met criteria for at least one other functional disorder highlights some of the challenges with a symptom-based classification approach. ${ }^{24}$ 


\section{Pathogenesis}

As with all functional disorders, the pathogenesis of symptoms is poorly understood. A range of studies has been conducted to explore potential physiological mechanisms in NCCP. Carbon dioxide inhalation studies demonstrate pharmacological provocation of anxiety-elicited chest pain and findings of increased sensitivity to pressure and pain in the oesophagus have been reported. ${ }^{25-28}$ Neurobiological studies on the pathogenesis of anxiety disorders have suggested increased sensory responsiveness. ${ }^{29}$ Interoceptive sensitivity and heartbeat perception have been investigated as mechanisms behind increased self-reporting of somatic sensations and related dysfunctional cognitive appraisal of what these sensations mean. ${ }^{30}$ While interesting, these findings have not yet translated into routine clinical practice. ${ }^{31,32}$

Purely biological models fall short of the well-known and observed interrelationship between psychological and physiological elements of persistent physical symptoms. Health attributions can influence the development and persistence of symptoms, as patients with medically unexplained symptoms are more likely to attribute their illness to physical causes compared with other factors. ${ }^{6}$ The most compelling models consider multiple factors contributing to the development and persistence of functional symptoms (Fig 1). Such models link the physiological impact of chronic stress with increased sensitisation to physical symptoms, resultant symptom hypervigilance, and behavioural responses including stress avoidance and symptom monitoring. ${ }^{7}$ These support observations that individuals with NCCP exhibit characteristic behaviours, including more time spent monitoring symptoms and accessing fewer coping strategies in comparison with both healthy controls and other patients with chronic pain. ${ }^{33}$ The particular relevance of these findings to the clinician is that lack of explanation as to what these symptoms are can increase anxiety, symptoms and symptom focus, perpetuating and worsening the cycle. ${ }^{7}$

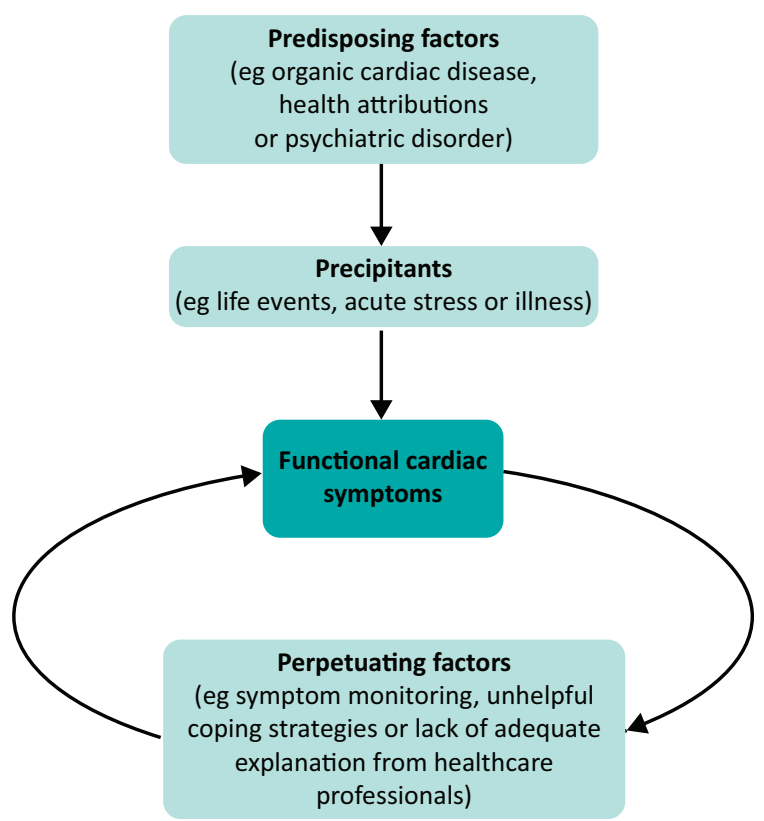

Fig 1. Model for the pathogenesis of functional cardiac disorders.

\section{How common are these problems?}

Reported prevalence rates vary according to study setting (eg primary versus secondary care) and criteria used to quantify or classify the clinical presentation. ${ }^{34}$ Estimates of medically unexplained symptoms seen in cardiology clinics have been reported at around $30-40 \%$ of presentations. ${ }^{6,35}$ Within primary care, symptoms associated with the cardiopulmonary system consistently feature in the most common types of symptoms described by $3-10 \%$ of all adult patients that have persistent medically unexplained symptoms. ${ }^{10,36}$ With the exception of NCCP, epidemiological studies have tended to focus on medically unexplained symptoms more widely rather than just cardiac presentations. Within this work, there are associations with female sex, younger age and being currently employed; however, there are differences for those with persistent symptoms. ${ }^{6,14}$

The epidemiology of NCCP, specifically, is relatively better studied. It is extremely common with a 1 -year prevalence of $14 \%$, accounting for $37-61 \%$ of emergency department presentations with chest pain. ${ }^{37-39}$ It is most common in younger adults and there is no significant gender difference. ${ }^{40,41}$ These demographic clues may help reassure the clinician providing a diagnosis to younger patients, but in older patients or those with more risk factors for coronary heart disease, they have minimal influence on clinical work up and investigations chosen.

\section{Clinical approach and diagnosis}

Unfortunately, the diagnosis of functional cardiac disorders is frequently delayed with patients sometimes consulting numerous healthcare professionals without receiving a satisfactory diagnosis. The non-specific nature of some cardiopulmonary symptoms and overlap with physical symptoms of anxiety, somatic symptoms of depression, upper gastrointestinal disorders and seizure disorders means that identification and management require a systematic approach (Table 1). This involves exclusion of serious pathology alongside consideration of and assessment for any comorbid mental health conditions from the outset. This allows early identification of any psychiatric cause for symptoms and evaluation of comorbid psychiatric disorders, which are very common in cardiac disease. Rigorous history, judicious use of investigations and good communication with the patient are essential. Differential diagnoses for NCCP, syncope and palpitations are broad and are described alongside suggested investigations in Table 2. Psychiatric differential diagnoses include affective disorders, substance misuse and post-traumatic stress disorder.

Among patients presenting with NCCP, exclusion of acute coronary syndromes is the priority, followed by gastrointestinal causes. ${ }^{42}$ Gastro-oesophageal reflux disease (GORD) has been demonstrated in $29-67 \%$ of individuals with NCCP, and frequency of heartburn is an independent risk factor for development of NCCP. ${ }^{40,43-45}$ In those without GORD, there is a controversial relationship to oesophageal dysmotility. ${ }^{26,46}$ There are, however, a substantial proportion of patients who experience functional dyspepsia. ${ }^{47}$ Within this patient group, NCCP could be considered a functional cardiac or gastrointestinal illness. ${ }^{8}$

The high prevalence of symptoms, the likelihood of a mixed clinical picture and the risks of harm from over-investigation all highlight the importance of a multidisciplinary approach with input from general practitioners, emergency medicine, cardiology, gastroenterology and psychiatry. ${ }^{21}$ With current service 
Table 1. Essential differential diagnoses and work-up for functional cardiac symptoms

\begin{tabular}{|c|c|c|}
\hline Symptom & Medical differential diagnosis & Work-up \\
\hline $\begin{array}{l}\text { Transient loss of } \\
\text { consciousness }\end{array}$ & $\begin{array}{l}\text { Trauma } \\
\text { Epilepsy } \\
\text { Syncope (cerebral hypoperfusion with rapid } \\
\text { onset, short duration of loss of consciousness } \\
\text { and complete recovery) including reflex syncope, } \\
\text { postural syncope and cardiac syncope }\end{array}$ & $\begin{array}{l}\text { History (personal or collateral): preceding symptoms, onset, } \\
\text { timings, prodrome, triggers, abnormal movements, associated } \\
\text { symptoms, recovery period, previous episodes, } \mathrm{PMH} \text { and FH } \\
\text { Examination: general, musculoskeletal, cardiac and } \\
\text { neurological } \\
\text { Lying/standing BP } \\
\text { 12-lead ECG } \\
\text { If recurrent, consider outpatient echocardiography, } \\
\text { cardiac rhythm monitoring, tilt-table testing and video } \\
\text { encephalography } \\
\text { If high-risk, admit for further investigations and/or treatment }\end{array}$ \\
\hline Palpitations & $\begin{array}{l}\text { Arrhythmia (ectopic beats, atrial fibrillation, atrial } \\
\text { flutter, other SVT, VT or bradycardia) } \\
\text { Sensing own heartbeat (may be normal or } \\
\text { could be result of physiological tachycardia or } \\
\text { hyperdynamic circulation) }\end{array}$ & $\begin{array}{l}\text { History: description of palpitation and associated symptoms } \\
\text { Examination: general and cardiac } \\
\text { 12-lead ECG } \\
\text { Blood tests: FBC, renal function, TFT, bone profile and troponin } \\
\text { Echocardiography } \\
\text { Ambulatory monitoring for appropriate time, depending on } \\
\text { frequency } \\
\text { Implantable loop recorder if palpitations associated with } \\
\text { syncope }\end{array}$ \\
\hline Chest pain & $\begin{array}{l}\text { Cardiac (eg angina, acute coronary syndrome, } \\
\text { myo-pericarditis, coronary emboli or mitral } \\
\text { prolapse) } \\
\text { Gastrointestinal (eg gastro-oesophagitis, reflux, } \\
\text { peptic ulcer, pancreatitis or cholecystitis) } \\
\text { Psychological (eg anxiety, depression, } \\
\text { hyperventilation or panic attacks) } \\
\text { Musculoskeletal (eg chest wall pain, rib fractures, } \\
\text { costochondritis or fibromyalgia) } \\
\text { Respiratory (eg pulmonary embolism, } \\
\text { pneumothorax or pneumonia) } \\
\text { Vascular (eg aortic dissection or aortitis) } \\
\text { Neurological (eg cervical or thoracic root pain) } \\
\text { Haematological (eg sickle cell disease) }\end{array}$ & $\begin{array}{l}\text { History: description of pain, associated symptoms, } \\
\text { exacerbating/relieving factors, frequency, similarity to previous } \\
\text { episodes, and risk factors for IHD, VTE and GORD. } \\
\text { Examination: general, respiratory and cardiac } \\
\text { 12-lead ECG } \\
\text { Blood tests: FBC, renal profile, LFT, CRP, fasting lipids, glucose, } \\
\text { troponin I/T and D-dimer } \\
\text { Chest X-ray, if suspected respiratory or musculoskeletal } \\
\text { pathology } \\
\text { OGD } \\
\text { CT coronary angiography }\end{array}$ \\
\hline
\end{tabular}

$\mathrm{BP}=$ blood pressure; $\mathrm{CRP}=\mathrm{C}$-reactive protein; $\mathrm{CT}=$ computed tomography; $\mathrm{ECG}=$ electrocardiography; $\mathrm{FBC}=$ full blood count; $\mathrm{FH}=$ family history; $\mathrm{GORD}=$ gastro-oesophageal reflux disease; IHD = ischaemic heart disease; LFT = liver function tests; OGD = oesophago-gastro-duodenoscopy; PMH = past medical history; SVT = supraventricular tachycardia; TFT = thyroid function tests; VT = ventricular tachycardia; VTE = venous thromboembolism.

Table 2. Psychiatric differential diagnosis of medically unexplained cardiac symptoms

\section{Psychiatric disorder}

Depression

Generalised anxiety disorder

Health anxiety

Panic disorder

Post-traumatic stress disorder

Substance use disorder

\section{Characteristic features}

Low mood and lack of interest

Prolonged, consistent worry, tension, and feelings of apprehension about everyday issues

Excessive concern about health and preoccupation with ideas that beliefs signify serious illness

Recurrent panic attacks

Flashbacks, nightmares, hypervigilance and emotional numbing

Harm to physical or mental health, cravings, loss of control, neglect of other aspects of life, intoxication and withdrawal

\section{Physical symptoms}

Fatigue, aches and pain (including chest pain)

Insomnia, restlessness and aches

Various

Chest pain, shortness of breath, paraesthesia and nausea

Chest pain and shortness of breath precipitated by a trigger that resembles initial trauma

Chest pain (sometimes due to myocardial ischaemia) in stimulant use; aches in opioid withdrawal 
configurations, however, this level of integration and coordinated working is rarely achieved. Indeed, it is usually initiated only after a patient has received multiple investigations and inadvertently been subjected to sustained uncertainty, fragmented care and inconsistent communication about the suspected cause of their symptoms. The finding that patients with NCCP tend to receive more investigations than those with cardiac chest pain highlights both the clinical and economic arguments for a multidisciplinary approach. $^{39}$

It is recommended that, when there are high levels of confidence in the likelihood of a functional presentation, investigation is kept to a minimum. In reality, this is difficult due to the potential consequences of missing a life-threating diagnosis and the mutual desire for reassurance in both the patient and physician. Both the rigour and reassurance of a multidisciplinary opinion may help ameliorate these difficulties. One caveat when considering early cessation of investigations is to ensure clinicians are aware of the higher risk of cardiovascular diseases in patients with mental health problems and the risk of diagnostic overshadowing in these patients' care. ${ }^{48,49}$

\section{Do medically unexplained cardiac symptoms mean there is a psychiatric disorder?}

Psychiatric conditions can be a comorbidity of, consequence of or explanation for persistent cardiac symptoms. Overall, there is a higher risk of psychiatric comorbidity in those who have persistent and/or multiple unexplained symptoms. ${ }^{38,50}$ Within the literature specifically on NCCP, psychiatric comorbidity is common with one study reporting $61 \%$ of patients meeting criteria for a psychiatric disorder. ${ }^{51}$

More specifically, cardiac symptoms can be a presenting symptom of an underlying psychiatric disorder, including depression, anxiety disorders, bodily distress disorder, posttraumatic stress disorder and substance misuse. A panic attack is a common reason for a young person to present to hospital with chest pain and is characterised by severe anxiety associated with signs of autonomic arousal, including palpitations or tachycardia, sweating, shaking, dry mouth, difficulty breathing, and chest pain. Treatment involves explanation of the physiological responses in anxiety followed by cognitive behavioural therapy (CBT) and/or a selective serotonin receptor uptake inhibitor (SSRI).

The high prevalence of both coronary heart disease and anxiety/ depression, and comorbidity with both of these conditions in the general population can mean that the clinical picture is often complex with multiple factors contributing to the presentation. All patients with cardiovascular disease should be screened for the presence of depression and anxiety.

Comorbidity of cardiovascular disease and psychiatric disorders and co-occurrence of both organic and functional cardiac symptoms is common. Approximately $30 \%$ of individuals with NCCP have a history of cardiac disease and it is those with a cardiac history who have more psychological distress. ${ }^{52,53}$ The best strategy is to ensure psychiatric comorbidities are identified, their treatment optimised and that a clear multidisciplinary management plan is in place.

\section{Clinical course and prognosis of functional symptoms}

When NCCP is adequately investigated and diagnosed, the mortality is low. ${ }^{51,54,55}$ However, in terms of ongoing chest pain, outcomes are often poor with $28-90 \%$ of patients still experiencing symptoms months to years later. ${ }^{54,56,57}$ Predictors of ongoing chest pain are female sex, a higher total number of symptoms and high levels of hypochondriasis. ${ }^{54,58,59}$

\section{Management}

\section{Interventions}

The most important aspect of management is patient-centred communication and an explanation of the diagnosis, which can be therapeutic in itself. A suggested approach is described in Table 3, but it must be tailored to the individual. Many symptoms are transient, so watchful waiting for 2 weeks is often justified. ${ }^{60}$ Thereafter, a stepped-care approach, where less invasive interventions are tried first, is recommended. ${ }^{60,61}$ All patients should be offered psychoeducation and active monitoring. ${ }^{61}$ Support groups and support with employment and education may also be offered. ${ }^{61}$ For those with persistent or moderately severe symptoms, CBT (which can be arranged via Improving Access to Psychological Therapy (IAPT)) has been recommended. ${ }^{60}$ Antidepressants, usually selective serotonin reuptake inhibitors, may also be used. ${ }^{60}$

In respect to NCCP, proton pump inhibitors (PPIs) produce an excellent response where GORD is present, but there is convincing evidence that they are no better than placebo when it is absent. ${ }^{62}$ A PPI may be worthwhile as a diagnostic and therapeutic trial. ${ }^{26}$ A Cochrane review of psychological interventions in NCCP found that psychological therapy was associated with a modest to moderate benefit with improvements in chest pain in the first 3 months and at subsequent follow-up; there was most evidence for CBT, but hypnotherapy was also suggested as an alternative. ${ }^{63}$ No adverse effects were identified. The use of antidepressants for NCCP is a plausible strategy as they could target comorbid depression and anxiety, and some have evidence for neuropathic pain. A systematic review of the use of antidepressant medication for NCCP found six randomised controlled trials, featuring sertraline, paroxetine, imipramine, venlafaxine and trazodone. ${ }^{64}$ Meta-analysis found that there were significant reductions in symptoms for sertraline, venlafaxine and imipramine with improvement in chest pain independent of antidepressant effect, but adverse effects were more common than in the placebo group. A suggested approach to management is shown in Fig 2.

\section{Multimodal and multidisciplinary care approaches}

Relative to functional gastrointestinal disorders, advances in diagnostics and therapeutics for functional cardiac symptoms remain relatively under-developed with recommendations mainly focusing on exclusion of acute coronary syndrome or coronary artery disease. ${ }^{8,47}$ Literature from both cardiac-specific functional symptoms and from study of other persistent symptoms suggests that integrated care using a biopsychosocial approach to diagnosis and management is the most effective way to manage patients with these conditions. ${ }^{65-67}$

Multidisciplinary treatment models have been tested and have shown positive results. ${ }^{66-68} \mathrm{~A}$ biopsychosocial multidisciplinary stepped-care clinic for chest pain involving both cardiology and psychology demonstrated a reduction in symptom burden and unplanned healthcare utilisation. ${ }^{67}$ Under this service model, patients receive a comprehensive integrated assessment, a biopsychosocial formulation for their symptoms and onward 
Table 3. Explaining the diagnosis of functional cardiac disorders

Task

Find out what the patient thinks the symptoms mean and what their concerns are

Ascertain how symptoms have previously been explained, including in unhelpful ways

Explain initial differential diagnosis

Explain findings of history, examination and investigations

State that these make a diagnosis of a functional cardiac disorder rather than one of the other diagnoses and why

Emphasise that this is a real and recognised condition

Explain the functional disorder in terms of the interaction between the mind and body

Consider giving an everyday example where the mind affects the circulatory system or drawing a diagram to illustrate the connections

Create opportunity to explore psychosocial stressors

Explain that there are good treatments available and it is possible to make a good recovery

\section{Example}

Are you able to tell me what you think is causing your symptoms? Is there anything that particularly worries you?

Who else have you seen for these symptoms? How have other healthcare professionals explained your symptoms? What did you take away from their explanations? I'm sorry you have sometimes gone away feeling that your symptoms weren't thought to be important. What I want to do today is to explore what you think is going on and how some of the assessment we have done can help us to come to a diagnosis.

There are many different causes of chest pain including acid reflux, narrowed blood vessels around your heart and, quite often, your body's physical response to stress. Are these things that you have thought about before? Are there any other diagnoses you have thought might be causing your symptoms?

Your examination and investigations have shown me that your heart structure is healthy and working well, which is reassuring as heart disease is not the cause of your symptoms. Do these tests make sense to you?

Your description of these symptoms and our investigation findings suggest you have what we call a functional cardiac disorder: difficult and worrying symptoms without damage to or disease of your heart. Is this a diagnosis you have heard about before?

This is a common and distressing problem that we don't fully understand but we do have treatments for.

We do not fully understand these conditions and suspect the causes are different in different people.

We have a lot of evidence that some people experience psychological distress physically: rather than appearing as, say, depressed, they experience actual physical pain. Not knowing what this pain means and the anxiety that causes can lead to a cycle where it gets worse and really affects your life. Do you ever find that your symptoms change according to how you are feeling?

The mind and the body affect each other a lot more than we realise. Blushing, for example, is a very physical response that can occur when we are embarrassed. When you are anxious or excited, your heart rate increases, and some people can even faint.

We don't fully understand what causes these problems and why they happen to some people. We do know that they seem to be more common in people who have gone through a difficult life event or who are under stress. I wondered if that resonates with you?

Are there any treatments that you had heard about or had been considering? There are good treatments available that focus on helping you understand and manage the symptoms. It is absolutely possible for you to make a good recovery and for these problems to stop impacting on your life. referral to CBT as indicated. Patient-reported benefits included better understanding and experience of control over their symptoms. $^{67}$

\section{Conclusion}

Functional cardiac symptoms are common and can be clinically challenging both to diagnose and, in the case of persistent symptoms, to treat. Clinicians should be aware of psychiatric differential diagnoses and comorbidities, and ensure early enquiry about relevant clinical features such as mood, health attributions, and impact on social and occupational functioning. Early identification or suspicion of comorbid anxiety and/or depression including panic disorder should be followed up with prompt referral to primary care and psychology (IAPT). The attitude of clinicians can influence clinical outcome. Too often, patients experience stigmatising attitudes towards these symptoms rather than receiving a biopsychosocial formulation that validates their experience, helps them understand and manage their condition, and helps them engage with evidence-based psychological interventions that can impact outcomes.

Overall, current UK service provision still fails to reflect the high prevalence of these conditions, the high rates of mental health comorbidity with cardiac disease, and the burden of disability and cost generated by them. ${ }^{12}$ Integration of mental health professionals as routine into cardiology services with the ability to work in a collaborative manner particularly around diagnosis remains an exception rather than the norm. This contributes to delays in diagnosis and treatment, fragmented care, poor patient experience and, potentially, poorer outcomes. Within the UK, recent national policy has highlighted the importance of better service provision for patients living with persistent symptoms, but 


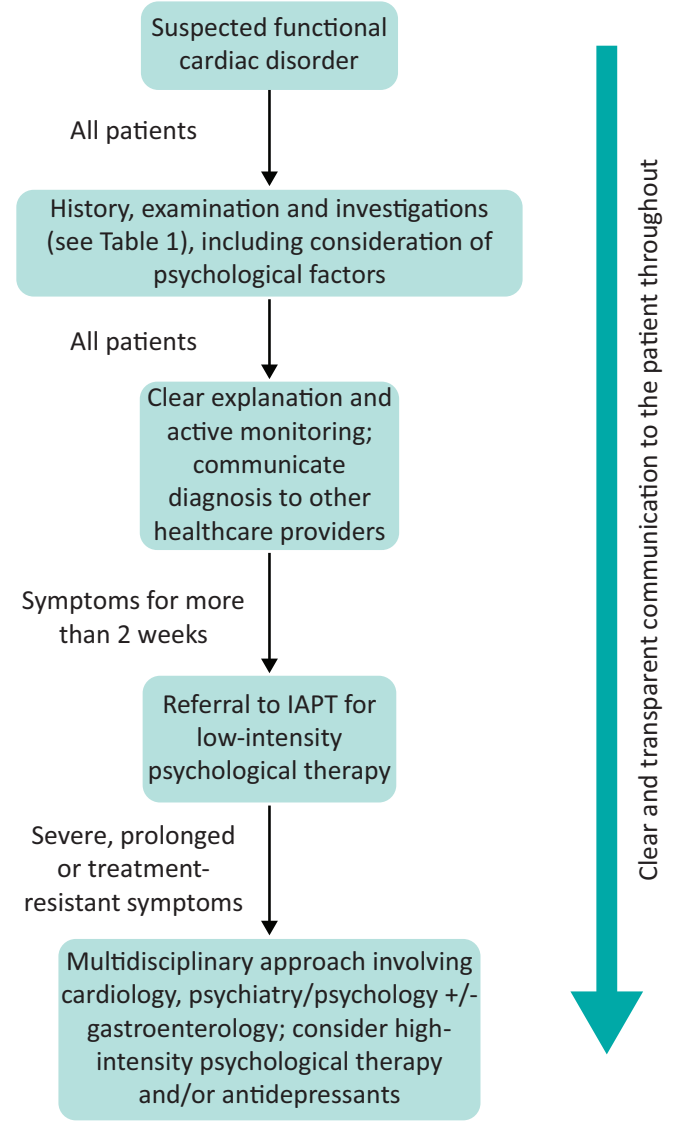

Fig 2. Management algorithm for functional cardiac disorders. IAPT = Improving Access to Psychological Therapy.

further work to develop effective treatment models and service configurations is needed. ${ }^{69,70}$

\section{References}

1 Auerback A, Gliebe PA. Iatrogenic heart disease. JAMA 1945;129: 338.

2 Fox M, Forgacs I. Unexplained (non-cardiac) chest pain. Clin Med 2006:6:445-9.

3 Tyrer P. Why health anxiety needs to be recognised in hospital practice. Clin Med 2020;20:339-42.

4 Gol JM, Rosmalen JGM, Gans ROB, Voshaar RCO. The importance of contextual aspects in the care for patients with functional somatic symptoms. Med Hypotheses 2020;142:109731.

5 Stone J, Wojcik W, Durrance D et al. What should we say to patients with symptoms unexplained by disease? The "number needed to offend". BMJ 2002;325:1449-50.

6 Nimnuan C, Hotopf M, Wessely S. Medically unexplained symptoms: An epidemiological study in seven specialities. J Psychosom Res 2001;51:361-7.

7 Deary V, Chalder T, Sharpe M. The cognitive behavioural model of medically unexplained symptoms: A theoretical and empirical review. Clin Psychol Rev 2007;27:781-97.

8 Campbell KA, Madva EN, Villegas AC, et al. Non-cardiac chest pain: a review for the consultation-liaison psychiatrist. Psychosomatics 2017:58:252-65.

9 Page L, Wessely S. Medically Unexplained symptoms: exacerbating factors in the doctor-patient encounter. J R Soc Med 2003;96:223-7.
10 Rosendal M, Olde Hartman TC, Aamland A et al. "Medically unexplained" symptoms and symptom disorders in primary care: prognosis-based recognition and classification. BMC Fam Pract 2017;18:18.

11 Aamland A, Malterud K, Werner EL. Patients with persistent medically unexplained physical symptoms: a descriptive study from Norwegian general practice. BMC Fam Pract 2014;15:107.

12 Bermingham SL, Cohen A, Hague J, Parsonage M. The cost of somatisation among the working-age population in England for the year 2008-2009. Ment Health Fam Med 2010;7:71-84.

13 Glombiewski JA, Rief W, Bösner S et al. The course of nonspecific chest pain in primary care. Arch Intern Med 2010;170:251.

14 van Eck van der Sluijs JF, Ten Have M, de Graaf R et al. Predictors of persistent medically unexplained physical symptoms: findings from a general population study. Front Psychiatry 2018;9:613.

15 Budtz-Lilly A, Schröder A, Rask MT et al. Bodily distress syndrome: A new diagnosis for functional disorders in primary care? BMC Fam Pract 2015;16:180.

16 Wessely S, White PD. There is only one functional somatic syndrome. Br J Psychiatry 2004;185:95-6.

17 van der Feltz-Cornelis CM, Elfeddali I, Werneke U, et al. A European research agenda for somatic symptom disorders, bodily distress disorders, and functional disorders: results of an estimate-talkestimate Delphi expert study. Front Psychiatry 2018;9:151.

18 Gureje O, Reed GM. Bodily distress disorder in ICD-11: problems and prospects. World Psychiatry 2016;15:291-2.

19 Burton C, Fink P, Henningsen P, Löwe B, Rief W. Functional somatic disorders: discussion paper for a new common classification for research and clinical use. BMC Med 2020;18:34.

20 Fink P, Schröder A. One single diagnosis, bodily distress syndrome, succeeded to capture 10 diagnostic categories of functional somatic syndromes and somatoform disorders. J Psychosom Res 2010;68:415-26.

21 Frieling T. Non-cardiac chest pain. Visc Med 2018;34:92-6.

22 Fass R, Navarro-Rodriguez T. Noncardiac chest pain. J Clin Gastroenterol 2008:42:636-46.

23 Ruddox V, Mathisen M, Otterstad JE. Prevalence and prognosis of non-specific chest pain among patients hospitalized for suspected acute coronary syndrome - a systematic literature search. BMC Med 2012;10:58.

24 Mudipalli RS, Remes-Troche JM, Andersen L, Rao SSC. Functional chest pain: esophageal or overlapping functional disorder. J Clin Gastroenterol 2007:41:264-9.

25 Stollman NH, Bierman PS, Ribeiro A, Rogers AI, Ribiero A. CO2 provocation of panic: symptomatic and manometric evaluation in patients with noncardiac chest pain. Am J Gastroenterol 1997:92:839-42.

26 Fass R, Dickman R. Non-cardiac chest pain: an update. Neurogastroenterol Motil 2006;18:408-17.

27 Hollerbach S, Bulat R, May A et al. Abnormal cerebral processing of oesophageal stimuli in patients with noncardiac chest pain (NCCP). Neurogastroenterol Motil 2000;12:555-65.

28 Sarkar S, Aziz Q, Woolf C], Hobson AR, Thompson DG. Contribution of central sensitisation to the development of noncardiac chest pain. Lancet 2000;356:1154-9.

29 Rodic D, Meyer AH, Lieb R, Meinlschmidt G. The association of sensory responsiveness with somatic symptoms and illness anxiety. Int J Behav Med 2016;23:39-48.

$30 \mathrm{Li} \mathrm{H}$, Zhang B, Hu Q et al. Altered heartbeat perception sensitivity associated with brain structural alterations in generalised anxiety disorder. Gen psychiatry 2020;33:e100057.

31 Weerdmeester ], van Rooij MM, Engels RC, Granic I. An Integrative Model for the Effectiveness of Biofeedback Interventions for Anxiety Regulation: Viewpoint. J Med Internet Res 2020;22:e14958.

32 Witthöft M, Bräscher AK, Jungmann SM, Köteles F. Somatic symptom perception and interoception. Z Psychol 2020;228:100-9. 
33 Cheng C, Wong W, Lai $\mathrm{K}$ et al. Psychosocial factors in patients with noncardiac chest pain. Psychosom Med 2003;65:443-9.

34 Henningsen P. Management of somatic symptom disorder. Dialogues Clin Neurosci 2018;20:23-31.

35 Hamilton J, Campos R, Creed F. Anxiety, depression and management of medically unexplained symptoms in medical clinics. J $R$ Coll Physicians Lond 1996;30:18-20.

36 Swanson LM, Hamilton JC, Feldman MD. Physician-based estimates of medically unexplained symptoms: a comparison of four case definitions. Fam Pract 2010;27:487-93.

37 Wong WM, Lam KF, Cheng C et al. Population based study of noncardiac chest pain in southern Chinese: prevalence, psychosocial factors and health care utilization. World ] Gastroenterol 2004;10:707-12.

38 Bjørnsen LP, Naess-Pleym LE, Dale J, Grenne B, Wiseth R. Description of chest pain patients in a Norwegian emergency department. Scand Cardiovasc J 2019;53:28-34.

39 Mol KA, Smoczynska A, Rahel BM et al. Non-cardiac chest pain: prognosis and secondary healthcare utilisation. Open Hear 2018;5:e000859.

40 Eslick GD, Jones MP, Talley NJ. Non-cardiac chest pain: prevalence, risk factors, impact and consulting-a population-based study. Aliment Pharmacol Ther 2003;17:1115-24.

41 Eslick GD, Talley NJ. Non-cardiac chest pain: predictors of health care seeking, the types of health care professional consulted, work absenteeism and interruption of daily activities. Aliment Pharmacol Ther 2004;20:909-15.

42 Gómez-Escudero O, Coss-Adame E, Amieva-Balmori M et al. The Mexican consensus on non-cardiac chest pain. Rev Gastroenterol Mex 2019;84:372-97.

43 Wong WM, Lai KC, Lau CP et al. Upper gastrointestinal evaluation of Chinese patients with non-cardiac chest pain. Aliment Pharmacol Ther 2002;16:465-71.

44 Dekel R, Martinez-Hawthorne SD, Guillen RJ, Fass R. Evaluation of symptom index in identifying gastroesophageal reflux diseaserelated noncardiac chest pain. J Clin Gastroenterol 2004;38:24-9.

45 Mohd H, Qua C-S, Wong C-H, Azman W, Goh K-L. Non-cardiac chest pain: prevalence of reflux disease and response to acid suppression in an Asian population. J Gastroenterol Hepatol 2009;24:288-93.

46 Dekel R, Pearson T, Wendel C, De Garmo P, Fennerty MB, Fass R. Assessment of oesophageal motor function in patients with dysphagia or chest pain - the Clinical Outcomes Research Initiative experience. Aliment Pharmacol Ther 2003;18:1083-9.

47 Black CJ, Drossman DA, Talley NJ, Ruddy J, Ford AC. Functional gastrointestinal disorders: advances in understanding and management. Lancet 2020;396:1664-74.

48 Woodhead C, Ashworth M, Broadbent M et al. Cardiovascular disease treatment among patients with severe mental illness: a data linkage study between primary and secondary care. Br J Gen Pract 2016;66:e374-81.

49 Jones S, Howard L, Thornicroft G. 'Diagnostic overshadowing': worse physical health care for people with mental illness. Acta Psychiatr Scand 2008;118:169-71.

50 Webster R, Norman P, Goodacre S, Thompson A. The prevalence and correlates of psychological outcomes in patients with acute non-cardiac chest pain: a systematic review. Emerg Med J 2012;29:267-73.

51 Potts SG, Bass CM. Psychological morbidity in patients with chest pain and normal or near-normal coronary arteries: a long-term follow-up study. Psychol Med 1995;25:339-47.

52 Mourad G, Jaarsma T, Strömberg A, Svensson E, Johansson P. The associations between psychological distress and healthcare use in patients with non-cardiac chest pain: does a history of cardiac disease matter? BMC Psychiatry 2018;18:172.

53 Fleet RP, Dupuis G, Marchand A et al. Panic disorder in coronary artery disease patients with noncardiac chest pain. J Psychosom Res 1998:44:81-90.
54 Wielgosz AT, Fletcher RH, McCants CB, McKinnis RA, Haney TL, Williams RB. Unimproved chest pain in patients with minimal or no coronary disease: a behavioral phenomenon. Am Heart J 1984;108:67-72.

55 Tew R, Guthrie EA, Creed FH et al. A long-term follow-up study of patients with ischaemic heart disease versus patients with nonspecific chest pain. J Psychosom Res 1995;39:977-85.

56 Dumville JC, MacPherson H, Griffith K, Miles JN V, Lewin RJ. Noncardiac chest pain: a retrospective cohort study of patients who attended a Rapid Access Chest Pain Clinic. Fam Pract 2007;24: $152-7$.

57 Eslick GD, Talley NJ. Natural history and predictors of outcome for non-cardiac chest pain: a prospective 4-year cohort study. Neurogastroenterol Motil 2008;20:989-97.

58 Jackson J, Fiddler M, Kapur $\mathrm{N}$ et al. Number of bodily symptoms predicts outcome more accurately than health anxiety in patients attending neurology, cardiology, and gastroenterology clinics. J Psychosom Res 2006;60:357-63.

59 Creed FH, Davies I, Jackson J et al. The epidemiology of multiple somatic symptoms. J Psychosom Res 2012;72:311-7.

60 Danish College of General Practitioners. Clinical guideline for general practice: Functional disorders. Danish College of General Practitioners, 2013 (translation 2016).

61 National Institute for Health and Care Excellence. Common mental health problems: identification and pathways to care: Clinical guideline [CG123]. NICE, 2011. www.nice.org.uk/guidance/cg123

62 Burgstaller JM, Jenni BF, Steurer J, Held U, Wertli MM. Treatment efficacy for non-cardiovascular chest pain: a systematic review and meta-analysis. PLoS One 2014;9:e104722.

63 Kisely SR, Campbell LA, Yelland MJ, Paydar A. Psychological interventions for symptomatic management of non-specific chest pain in patients with normal coronary anatomy. Cochrane Database Syst Rev 2015;2015:CD004101.

64 Nguyen TMT, Eslick GD. Systematic review: the treatment of noncardiac chest pain with antidepressants. Aliment Pharmacol Ther 2012;35:493-500

65 Clare A, Andiappan M, MacNeil S, Bunton T, Jarrett S. Can a pain management programme approach reduce healthcare use? Stopping the revolving door. Br J Pain 2013;7:124-9.

66 Chambers JB, Marks EM, Russell V, Hunter MS. A multidisciplinary, biopsychosocial treatment for non-cardiac chest pain. Int J Clin Pract 2015:69: 922-7.

67 Marks EM, Chambers JB, Russell V, Hunter MS. A novel biopsychosocial, cognitive behavioural, stepped care intervention for patients with non-cardiac chest pain. Heal Psychol Behav Med 2016;4:15-28.

68 Chambers JB, Marks EM, Hunter MS. The head says yes but the heart says no: what is non-cardiac chest pain and how is it managed? Heart 2015;101:1240-9.

69 Chalder T, Patel M, James K et al. Persistent physical symptoms reduction intervention: a system change and evaluation in secondary care (PRINCE secondary) - a CBT-based transdiagnostic approach: study protocol for a randomised controlled trial. BMC Psychiatry 2019;19:307.

70 Geraghty K, Scott MJ. Treating medically unexplained symptoms via improving access to psychological therapy (IAPT): major limitations identified. BMC Psychol 2020;8:13.

Address for correspondence: Dr Jonathan Rogers, University College London Division of Psychiatry, Maple House, 149

Tottenham Court Road, London W1T 7BN, UK.

Email: jonathan.rogers@ucl.ac.uk

Twitter: @drjprogers 